\title{
Relação entre o Índice de Sustentabilidade e os Indicadores Econômico- financeiros das empresas de energia brasileiras
}

\author{
Relationship between Sustainability Index and the Financial-Economic Indicator of the Brazilian energy companies
}

\section{Luiza Betânia Fasolin', Itzhak David Simão Kaveski², Tânia Cristina Chiarello³, Rodrigo Barraco Marassi ${ }^{4}$, Nelson Heinn ${ }^{5}$}

\author{
'Faculdade Educacional de Dois Vizinhos - FAED/UNISEP, Brasil \\ ${ }^{2}$ Universidade Federal de Mato Grosso do Sul - UFMS/CPAN, Brasil \\ 3;4;5 Fundação Universidade Regional de Blumenau - FURB, Brasil
}

\section{Resumo}

A sociedade está cada vez mais exigindo que as organizações considerem as dimensões econômica, social e ambiental nas suas atividades. Com isso, as informações que envolvem práticas de sustentabilidade ganham importância. Este estudo refere-se às práticas de sustentabilidade das empresas geradoras e distribuidoras de energia brasileiras que são listadas na BM\&FBovespa e possui como objetivo verificar a relação entre o índice de sustentabilidade e os indicadores econômico-financeiros das empresas de energia listadas na BM\&FBovespa. A amostra é composta por 31 companhias que enviaram seus relatórios de sustentabilidade do ano de 2010 para a Aneel. A metodologia utilizada foi o método quantitativo descritivo, utilizando a técnica documental, e a regressão linear múltipla com a utilização do software estatístico IBM ${ }^{\circledR}$ SPSS $®$ versão 21. Para a coleta de dados, foi elaborado um check list para evidenciar os aspectos ambiental, social e econômico divulgados pelas empresas. Mas também utilizou-se da Economática para as variáveis econômico-financeiras. Os resultados encontrados demonstram que os indicadores econômico-financeiros do tamanho, rentabilidade e endividamento das empresas geradoras e distribuidoras de energia elétrica brasileira não influenciam o nível de evidenciação das práticas de sustentabilidade destas companhias.

Palavras-chave: Sustentabilidade. Evidenciação. Indicador Econômico-Financeiro.

\begin{abstract}
Society is increasingly demanding that organizations consider the economic, social and environmental issues into their activities. With this, the information that involve sustainability practices gain importance. This study refers to the sustainability practices of companies generating and distributing energy in Brazil that are listed on the BM\&FBovespa and has as objective to verify the influence between the sustainability index and the financial and economic indicators of energy companies listed on the BM\&FBovespa. The sample consists of 31 companies that sent their sustainability reports in 2010 to Aneel. The methodology used was descriptive quantitative method, using the technical documentation, and multiple linear regression using the statistical software IBM $₫$ SPSS $₫$ version 21. For data collection, a checklist has been prepared to highlight the environmental, social and economic disclosed by companies. But it was also used Economática for economic-financial variables. The results show that the financial and economic indicators of size, profitability and indebtedness of generating and distributing electricity Brazilian did not influence the level of disclosure of sustainability practices of these companies.
\end{abstract}

Keywords: Sustainability. Disclosure. Financial-Economic Indicator. 


\section{INTRODUÇÃO}

O desenvolvimento sustentável é uma preocupação crescente na sociedade, em que as empresas começam a direcionar esforços no sentido de buscar soluções para a problemática ambiental (CAPRA, 2005).

Os consumidores não mais desejam apenas um bom produto ou serviço a um preço justo, mas almejam saber se o processo produtivo não impacta de maneira danosa o meio ambiente. Por esse motivo, as entidades passaram a incluir nas suas estratégias a sustentabilidade com vistas à preservação ambiental, a transparência das ações empresariais, o crescimento econômico do País e o compromisso com o bem-estar social (AZEVEDO, 2006).

As organizações buscam atingir a sustentabilidade em suas três dimensões (econômica, social e ambiental). Essa preocupação sistêmica ficou conhecida como triple bottom line (ELKINGTON, 2012), sendo cada vez mais cobrada pela sociedade. Alguns sintomas dessa cobrança podem ser identificados com a evidenciação nos relatórios de sustentabilidade que passaram a ser utilizados para a prestação de contas das organizações (NUNES et al., 2010).

Segundo Ponte e Oliveira (2004, p. 9), "as empresas podem adotar diferentes formas de evidenciação, mas devem fornecer informações em quantidade e qualidade que atendam às necessidades dos usuários das demonstrações contábeis". Considera-se que as empresas que operam em setores que causam maiores impactos ambientais são mais cobradas quanto às demandas de informação para a sociedade (KPMG, 2011). Setores como o de geração e distribuição de energia causam grande impacto ambiental e possuem relevância econômica para o desenvolvimento do País.

As empresas estão começando a preocupar-se com sua atuação referente aos aspectos socioambientais, descobrindo que a responsabilidade social e ambiental pode desencadear em uma boa vantagem competitiva relativa ao mercado (PARENTE; GELMAN, 2006). Algumas características podem influenciar na evidenciação das práticas de sustentabilidade, como o tamanho, a rentabilidade e o endividamento das empresas.

Diante disso, surge a seguinte questão de pesquisa: Qual a relação entre o índice de sustentabilidade e os indicadores econômico-financeiros das empresas de energia listadas na BM\&FBovespa? Assim, o objetivo do estudo é verificar a relação entre o índice de sustentabilidade e os indicadores econômico-financeiros das empresas de energia listadas na BM\&FBovespa.

Este estudo mostra-se relevante visto que a cada dia crescem os questionamentos contra o modelo desenvolvimentista alicerçado puramente nos aspectos econômicos e aumenta a conscientização de que é inviável a expansão organizacional amparada na exploração desmedida de recursos finitos. Tinoco e Kraemer (2011, p.1) afirmam que "a questão ambiental tem se tornado mais frequentemente discutida à medida que se constata que a interferência do ser humano sobre os sistemas naturais pode comprometer tanto a qualidade de vida da atual população mundial como a vida das próximas gerações".

A pesquisa justifica-se ainda pela necessidade de saber se as características econômico-financeiras influenciam as práticas de sustentabilidade, por ser um tema recorrente em que surgem diversas dúvidas desta influência. Segundo Dalmácio e Paulo (2004, p. 7) "as empresas possuem um compromisso social com a sociedade, não devendo mais almejar somente o lucro [...], pois as empresas tornaram-se peças fundamentais para o desenvolvimento econômico e social da nação". O setor de energia elétrica possui grande impacto ambiental relevância econômica para o país.

\section{MÉTODO}

O método de pesquisa utilizado neste estudo teórico-empírico foi o descritivo, pois, conforme Beuren et al. (2004, p. 81), configura-se em um "estudo intermediário entre a pesquisa exploratória e a explicativa, ou seja, não é tão preliminar como a primeira e não tão aprofundada como a segunda. Nesse contexto, descritivo significa identificar, relatar, comparar, entre outros".

Foi utilizado neste estudo o método quantitativo, que apresenta como principal característica o emprego da quantificação tanto no processo de coleta de informações quanto no seu tratamento, valendo-se de técnicas estatísticas (RICHARDSON, 1999). O método quantitativo lida com um conjunto de técnicas de pesquisa e de análise que permite relacionar descobertas sobre padrões de comportamento com implicações nas teorias já existentes. Para Creswell (2009), os estudos quantita- 
tivos objetivam testar ou verificar uma teoria, não tendo a pretensão de desenvolver uma teoria nova. Assim, o pesquisador apresenta uma teoria, coleta dados e realiza testes com o intuito de confirmá-la ou refutá-la, a partir dos resultados obtidos.

Quanto à técnica de pesquisa, neste trabalho utilizou-se a documental. Segundo Marconi e Lakatos (2002, p. 62) quanto à característica da pesquisa documental que "[...] a fonte de coleta de dados está restrita a documentos, escritos ou não, constituindo o que se denomina de fontes primárias. Estas podem ser recolhidas no momento em que o fato ou fenômeno ocorre, ou depois".

A amostra da presente pesquisa é constituída de empresas geradoras e distribuidoras de energia elétrica no Brasil que estão listadas na BM\&FBovespa e que enviam seus relatórios de sustentabilidade para a Aneel. Esses relatórios foram adquiridos por intermédio do site da Agência, totalizando 31 empresas, excluindo da amostra as holdings e aquelas que eram apenas de transmissão de energia. O ano utilizado foi o de 2010 , por ser um ano em que todas as empresas enviaram seus relatórios de sustentabilidade para a Agência.

A utilização de empresas geradoras e distribuidoras de energia se deu por serem empresas com grande impacto ambiental, das quais a sociedade cobra atitudes, principalmente por serem companhias listadas na BM\&FBovespa e terem grande relevância na economia brasileira.

Para a coleta de dados, foi elaborado um check list com 50 itens das práticas de sustentabilidade, entre elas práticas ambientais, sociais e econômicas. Foi examinada a evidenciação e a não evidenciação dos itens do check list nos relatórios de sustentabilidade, em que as companhias foram avaliadas em " 1 " para evidenciação e " 0 " para a não evidenciação das informações. Os check lists utilizados para evidenciar as práticas de sustentabilidade são apresentados nos quadros a seguir:

\section{Quadro 1 - Diretrizes para Evidenciação Ambiental}

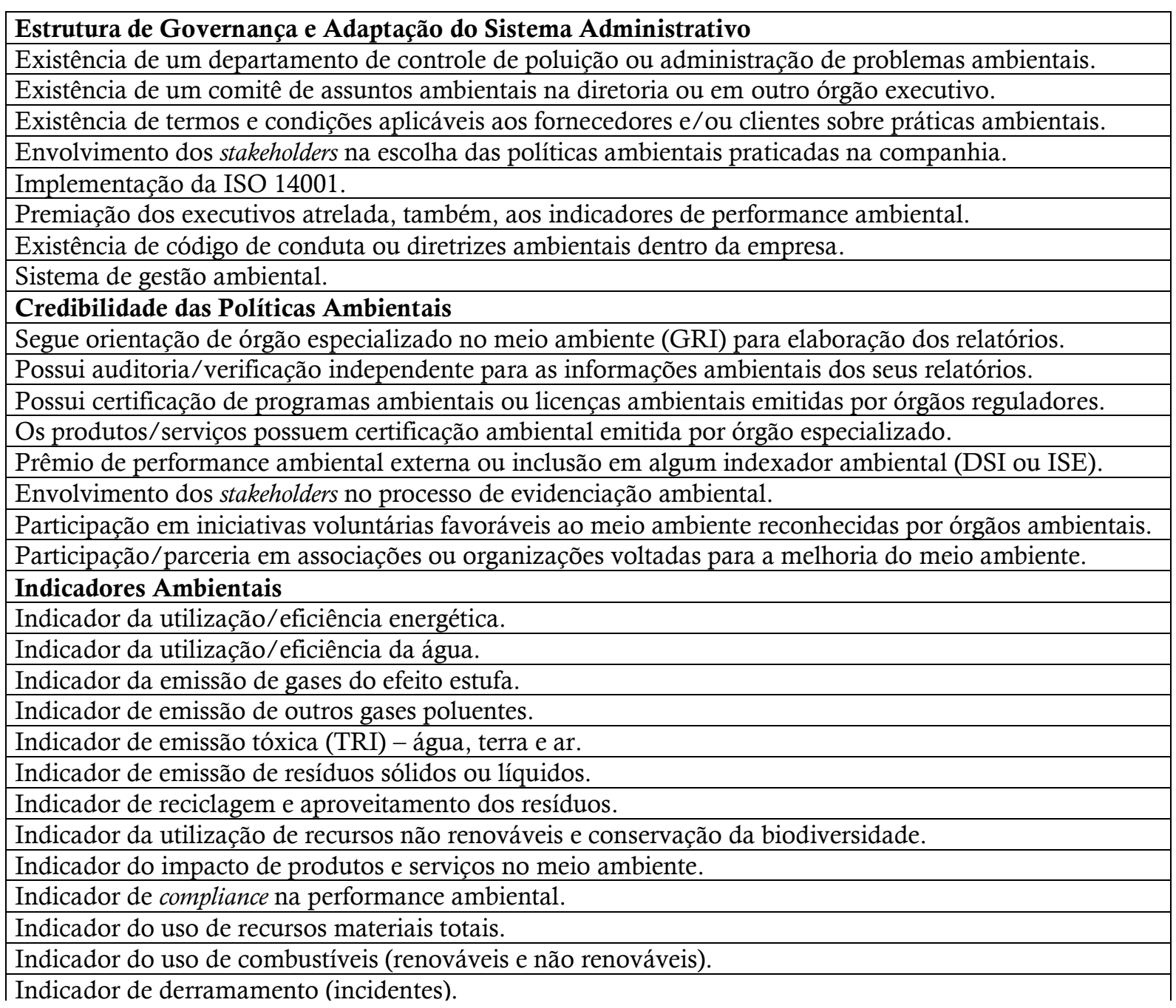


\begin{tabular}{|l|}
\hline Indicadores do aquecimento global (neutralização). \\
\hline Litígios e Processos Ambientais \\
\hline Processos judiciais ambientais formalizados contra a empresa. \\
\hline Autuações e notificações ambientais recebidas pela empresa. \\
\hline Processos ambientais cabíveis contra a empresa. \\
\hline Criação de reserva/provisão para contingências ambientais. \\
\hline
\end{tabular}

Fonte: Adaptado de Mussoi e Van Bellen (2010).

Quadro 2 - Diretrizes para Evidenciação Social

\begin{tabular}{|l|}
\hline Publica o Balanço Social? \\
\hline Publica a DVA? \\
\hline $\begin{array}{l}\text { Evidencia no relatório da administração, no relatório de sustentabilidade e/ou nas notas explicativas } \\
\text { dados relativos à interação da entidade com o ambiente externo e ao relacionamento com a comunidade, } \\
\text { clientes, fornecedores e incentivos decorrentes dessa interação? }\end{array}$ \\
\hline Utiliza critérios de responsabilidade social para a seleção de fornecedores? \\
\hline Evidencia informações relativas a ações trabalhistas? \\
\hline Evidencia o número de reclamações recebidas por meio dos órgãos de proteção e defesa do consumidor? \\
\hline
\end{tabular}

Fonte: Adaptado de Vieira (2006) apud Beuren et al. (2009).

Quadro 3 - Diretrizes para Evidenciação Econômica

\begin{tabular}{|l|}
\hline Sumário de dinheiro economizado pela companhia com ações de iniciativa ambiental. \\
\hline Quantia gasta para melhorar a performance ambiental/ecoeficiência em projetos ambientais. \\
\hline Quantia gasta em multas ou processos ambientais. \\
\hline Relação da distribuição dos gastos ambientais. \\
\hline Evidencia a remuneração bruta segregada por empregados, administradores, terceirizados e autônomos? \\
\hline Evidencia gastos com a previdência privada? \\
\hline Evidencia gastos com a cultura, tanto com seu público interno quanto com o externo? \\
\hline Evidencia participação dos funcionários nos resultados? \\
\hline Evidencia valor de indenizações e multas pagas a empregados por determinação da justiça? \\
\hline Evidencia investimentos em educação? \\
\hline
\end{tabular}

Fonte: Adaptado de Mussoi e Van Bellen (2010); Vieira (2006) apud Beuren et al. (2009).

A partir destes check lists pode-se conceder a cada empresa um índice que representa a porcentagem de evidenciação das práticas de sustentabilidade. O máximo de indicadores possíveis que cada entidade poderia evidenciar era de 50 itens. Este índice será a variável independente SUST, utilizada na análise de regressão.

Foram identificadas as características das empresas objeto do estudo quanto ao tamanho, rentabilidade e endividamento. Essas variáveis apresentadas no Quadro 4 foram coletadas por meio da Economática. Os procedimentos estatísticos foram regressão linear múltipla por meio do software estatístico IBM® SPSS ${ }^{\circledR}$ versão 21.

Foram encontradas limitações na pesquisa, como pelos relatórios de sustentabilidade não seguirem um padrão, como o GRI, que é um modelo internacional, o que dificultou a coleta dos dados, fazendo com que houvesse uma leitura integral dos respectivos relatórios.

Quadro 4 - Diretrizes para Evidenciação Econômica

\begin{tabular}{|c|c|c|}
\hline $\begin{array}{c}\text { Variável de } \\
\text { Análise }\end{array}$ & Medidas & Referências \\
\hline Tamanho & LN do ativo total & $\begin{array}{c}\text { Hackston e Milne (1996); Cunha e } \\
\text { Ribeiro (2008); Rover et al. (2008). }\end{array}$ \\
\hline Rentabilidade & ROA = Lucro Líquido/ Ativo Total & $\begin{array}{c}\text { Hackston e Milne (1996); Russo e } \\
\text { Fouts (1997); D'Arcimoles; Trebucq } \\
\text { (2002); Cunha e Ribeiro (2008). }\end{array}$ \\
\hline
\end{tabular}




$$
\begin{array}{|c|c|}
\hline \multirow{3}{*}{\text { Endividamento }} & \begin{array}{c}
\text { PCT }=\text { (Passivo Circulante + Passivo não } \\
\text { Circulante) / Patrimônio Líquido } \\
\text { CE = Passivo Circulante/ (Passivo } \\
\text { Circulante + Passivo não Circulante) }
\end{array} \\
\hline
\end{array}
$$

Lanzana (2004); Cunha e Ribeiro (2008).

Fonte: Elaborado pelos autores

\section{REVISÃO DA LITERATURA}

A revisão bibliográfica apresenta os conceitos fundamentais que sustentam a pesquisa, tornando-se a principal fonte para a análise dos dados coletados. Assim, os tópicos a seguir abordam a evidenciação das práticas de sustentabilidade, as características das empresas de energia e estudos anteriores.

\section{I EVIDENCIAÇÃO DAS PRÁTICAS DE SUSTENTABILIDADE}

O modelo econômico estava alicerçado na visão de que os recursos ecológicos são inesgotáveis, em especial os energéticos. Um novo modo de gerir os recursos naturais se faz premente, crescendo uma sensibilização coletiva no sentido de que as instituições precisam passar por uma mudança fundamental, pois formas arcaicas de gestão não atendem mais ao intuito de desenvolvimento sustentável (DREHER; CASAGRANDE; GOMES, 2012; SACHS; LOPES; DOWBOR, 2010).

Os recursos naturais vindos do meio ambiente não podem ser vistos apenas como insumo para o processo produtivo, posto que são finitos. Este paradigma idealizado pelo prisma capitalista precisa ser revisto. As tomadas de decisões das organizações devem levar em conta a necessidade de reavaliação contínua dos recursos utilizados, assegurando que as futuras gerações também tenham acesso a estes (HOLDREN; EHRLICH, 1971).

O conceito de sustentabilidade procede da definição do desenvolvimento sustentável, que surgiu como um novo "modelo" que objetiva a satisfação das necessidades presentes sem comprometer a capacidade das gerações futuras de suprirem suas próprias necessidades (WCED, 1987).

Em 1972, em Estocolmo, ocorreu a Conferência das Nações Unidas sobre o Ambiente Humano, abordando pela primeira vez o assunto que trata das dependências entre o meio ambiente e o desenvolvimento, colocando a dimensão do meio ambiente na agenda internacional (SACHS, 2009). Desde essa época, o tema aos poucos passou a fazer parte das estratégias organizacionais. O entendimento sobre responsabilidade social e sustentabilidade corporativa ganhou mais força a partir da segunda metade da década de 1990, mostrando a importância de valorizar relacionamentos de longo prazo com os stakeholders (fornecedores, clientes, acionistas, empregados e comunidade em geral) e reconhecendo o impacto da produção na degradação do meio ambiente (POLONSKI; SUCHARD; SCOTT, 1997).

Elkington (2012) discorre que o desenvolvimento sustentável deve atender, de maneira sistêmica, a três dimensões essenciais: econômica, social e ambiental. O pilar econômico trata das consequências financeiras das ações da empresa para os stakeholders; o pilar social refere-se à participação da manutenção e aperfeiçoamento do sistema no que diz respeito aos direitos e responsabilidades; e o pilar ambiental defende a conservação e o manejo dos recursos naturais.

A produção mais limpa, a participação em projetos de desenvolvimento sustentável e a geração de produtos ecológicos, ou seja, a busca pela sustentabilidade vem movimentando a sociedade e o mercado, transformando-se em uma batalha entre governos, empresas, consumidores e ativistas. A busca pela sustentabilidade requer recursos, inovações e equipamentos, entre outros esforços, com as quais muitas organizações, principalmente as de países em desenvolvimento, não conseguem competir (DREHER; CASAGRANDE; GOMES, 2012).

Simon (1971) afirma que muitos problemas socioambientais foram causados por decisões que visavam atender apenas à dimensão econômica, dentro do conceito da racionalidade limitada. No campo organizacional, a ênfase está na área econômica, em detrimento das demais, ou seja, nem sempre são consideradas todas as dimensões de sustentabilidade.

Governança corporativa é um sistema pela qual as sociedades são dirigidas e monitoradas, envolvendo o relacionamento entre o Conselho de Administração, Conselho Fiscal, Diretoria, Auditoria Independente e Acionistas. A governança corporativa possui como premissa a transparência das demonstrações, podendo ser um fator essencial para o acesso das empresas ao mercado de capitais (IBGC, 2007).

A demanda da sociedade pela transparência dos aspectos relacionados à sustentabilidade passou 
a ganhar espaço e importância entre as informações que são fornecidas pelas organizações (TINOCO; ROBLES, 2006). Por esse motivo, as empresas passaram a utilizar os relatórios de sustentabilidade para prestação de contas no contexto de governança corporativa. Esses relatórios englobam as dimensões de sustentabilidade: econômica, social e ambiental, passando a ser percebidos como meio de formalização do cumprimento de como as organizações colaboram em termos de responsabilidade social (KOLK, 2005).

Em virtude das preocupações sobre a evidenciação das práticas sustentáveis, encontra-se o GRI, um modelo de relatório de sustentabilidade internacional, desenvolvido para ajudar as empresas na divulgação de seu desempenho ambiental, social e econômico, aumentando a sua prestação de contas (DI DOMÊNICO, 2012). Apesar de existirem tentativas para normatizar a forma pela qual as informações ambientais e sociais devem ser divulgadas, como é o caso do modelo GRI e do Balanço Social IBASE (Instituto Brasileiro de Análises Sociais e Econômicas), não há no Brasil a obrigatoriedade de evidenciação dessas práticas de sustentabilidade (ROVER et al., 2008).

Ciliberti et al. (2008) afirma que clientes preferem adquirir produtos ou serviços e investir em ações de empresas com políticas de atuação na preservação ambiental e bons comportamentos de cidadania. Essas práticas fortalecem a entidade, passando a obter maior confiança da sociedade. A alta performance social corporativa gera na empresa uma melhor habilidade para atração de capital e parceiros de negócios, gerando ganhos de reputação frente à comunidade corporativa e ao público (ORLITZY; SCHMIDT; RYNES, 2003).

Nesse novo modelo estratégico, os interesses dos acionistas dividem espaços com as demandas da comunidade, dos funcionários, do governo, dos fornecedores e dos clientes. Para agregar valor a todos esses stakeholders e não perder sua atratividade, a empresa não poderá negligenciar nenhuma das três dimensões da sustentabilidade: econômica, social e ambiental. Algumas características das empresas são fatores que podem influenciar na determinação da evidenciação do relatório de sustentabilidade, e serão apresentadas no tópico a seguir.

\subsection{CARACTERísticAS DAS EMPRESAS DE ENERGIA}

Ao considerar questões socioambientais sob o ponto de vista empresarial, surgem dúvidas no que diz respeito ao aspecto econômico e financeiro da entidade. Miles e Covin (2000) apontam que os investimentos feitos para proteção ambiental são vistos como negativos para o desempenho financeiro da empresa, sendo recursos que poderiam ser aplicados na produção. Mas por outro lado, Parente e Gelman (2006) afirmam que as entidades começam a preocupar-se com sua atuação sobre os aspectos socioambientais, descobrindo que a responsabilidade social e ambiental pode desencadear em uma boa vantagem competitiva relativa ao mercado.

Algumas características podem influenciar na evidenciação das práticas de sustentabilidade, como o tamanho, a rentabilidade e o endividamento das empresas de energia. Rover et al. (2008, p. 8) afirmam que "grandes empresas têm um maior efeito sobre sua comunidade, um grupo maior de stakeholders que a influenciam, e consequentemente custos políticos devido a sua visibilidade perante à sociedade, o que poderia atrair a atenção do governo e do mercado como um todo".

Hackston e Milne (1996) verificaram em sua pesquisa os determinantes da evidenciação social e ambiental das 50 maiores empresas da Nova Zelândia, utilizando as variáveis: rentabilidade, tamanho e setor. Os resultados demonstraram que o setor e o tamanho justificam o nível de evidenciação das companhias.

A variável tamanho é relevante porque as despesas sociais e ambientais podem variar entre grandes e pequenas empresas. O tamanho de uma empresa é medido por meio de três alternativas: total das vendas, ativos totais e número de empregados (D'ARCIMOLES; TREBUCQ, 2002).

Russo e Fouts (1997) afirmam em seus estudos que o alto desempenho ambiental está associado com aumento da rentabilidade, principalmente em indústrias de setores de maior crescimento. Quanto maior o crescimento do setor, maior o impacto positivo do desempenho ambiental na rentabilidade. Isso acontece pela influência das políticas públicas, dando à empresa vantagem competitiva.

Bertagnolli, Ott e Macena (2006) verificaram em sua pesquisa se existia influência dos investimentos sociais e ambientais no desempenho financeiro das empresas, utilizando onze indicadores sociais internos, dez indicadores sociais externos e dois indicadores ambientais como variáveis independentes e a receita líquida e o resultado operacional como variáveis dependentes. Concluíram haver relação positiva entre os indicadores sociais e o desempenho econômico das empresas. 
Em relação ao indicador de endividamento, Lanzana (2004) afirma que empresas com maior grau de endividamento tendem a apresentar maior nível de divulgação, com o objetivo de fornecer maiores informações a seus credores, que passam a monitorar assiduamente a situação da empresa.

A relação da evidenciação de práticas de sustentabilidade com a situação econômico financeira das empresas é tema recorrente de diversos estudos, apesar dos questionamentos que surgem neste meio, sendo o assunto do próximo tópico.

\subsection{ESTUDOS ANTERIORES}

A evidenciação de práticas de sustentabilidade e o desempenho econômico-financeiro das empresas são temas recorrentes, acerca do qual inúmeras pesquisas podem ser observadas tanto na literatura nacional quanto na internacional. Os estudos se motivam pelo assunto ser de grande importância para as empresas que buscam demonstrar a relevância concedida para questões ambientais e sociais, além da financeira.

Hackston e Milne (1996) verificaram os determinantes da evidenciação social e ambiental das 50 maiores empresas da Nova Zelândia, utilizando variáveis como rentabilidade, tamanho e setor. Concluíram por meio da pesquisa que o setor e o tamanho justificam o nível de evidenciação das companhias.

Nossa (2002) analisou o conteúdo dos relatórios ambientais no âmbito internacional de empresas do setor de papel e celulose, verificando como estava o nível de evidenciação de informações ambientais. Os resultados encontrados apresentam que a evidenciação de informações ambientais das empresas do setor de papel e celulose diverge entre as companhias com relação ao tamanho da empresa, ao país de localização e ao tipo de relatório (financeiro ou específico), mostrando-se ainda incipiente e frágil em relação ao nível de confiabilidade e comparabilidade das informações.

Von Arx e Ziegler (2008) examinaram nova evidência empírica para o efeito de responsabilidade social empresarial sobre o desempenho financeiro das organizações nos EUA e na Europa, no período de 2003 a 2006. Os resultados encontrados demonstraram que empresas com atividades ambientais e sociais eram mais valorizadas no mercado se comparadas a outras empresas do mesmo setor. No entanto, os retornos da ação mensal no período não foram lineares, sendo mais robustos nos EUA que na Europa.

Braga, Oliveira e Salotti (2009) avaliaram a influência de determinadas variáveis (tamanho, desempenho, endividamento, riqueza criada, natureza da atividade, controle acionário e governança corporativa) sobre o nível de divulgação ambiental nas demonstrações contábeis de empresas brasileiras. Foram analisadas as demonstrações contábeis de 108 companhias de capital aberto listadas na BM\&FBovespa referente ao exercício social de 2006. As evidências analisadas sugerem que as variáveis do tamanho, riqueza criada e natureza da atividade exercem influência direta e significativa sobre o nível de divulgação ambiental.

\section{APRESENTAÇÃO E ANÁLISE DOS DADOS}

Com base no relatório de sustentabilidade disponibilizado no site da ANEEL de cada empresa da amostra, extraíram-se informações por meio da análise de conteúdo das práticas de sustentabilidade. Os dados econômico-financeiros foram extraídos por meio da Economática. A partir destes dados coletados foi realizada a análise descritiva, considerando cada variável, conforme apresentado na Tabela 1.

Tabela 1 - Estatística descritivas das variáveis

\begin{tabular}{c|c|c|c|c}
\hline Variável & Mínimo & Máximo & Média & Desvio Padrão \\
\hline SUST & 0,08 & 0,92 & 0,72 & 0,19 \\
\hline TAM & 4,70 & 8,17 & 6,62 & 0,57 \\
\hline ROA & $-0,05$ & 0,17 & 0,07 & 0,06 \\
\hline PCT & 0,38 & 5,51 & 1,82 & 1,15 \\
\hline CE & 0,19 & 0,98 & 0,40 & 0,14 \\
\hline
\end{tabular}


Por meio da Tabela 1, constata-se que a sustentabilidade (SUST) das empresas da amostra foi de $72 \%$ em média, sendo uma porcentagem elevada. A SUST é a variável dependente desta pesquisa, que inclui itens econômicos, sociais e ambientais. Possui um índice de evidenciação de sustentabilidade de $8 \%$ no mínimo e $92 \%$ no máximo. Lembrando que esta variável é a única dummy da pesquisa, que era considerado 1 para o item que era evidenciado e 0 se não, sendo composto de no máximo 50 itens.

Se tratando das características econômico-financeiras da empresa, as variáveis que tratam do tamanho da entidade são representadas pelo logaritmo natural do ativo total (TAM), possuindo uma média de representatividade de 6,62. A variável que representa a rentabilidade da empresa, ou seja, a ROA demonstraram um índice de 0 , em média respectivamente, além disso é a única variável que possui índice negativo em seu mínimo.

As variáveis que representam o endividamento da amostra desta pesquisa são compostas pelas variáveis que demonstram o endividamento em relação ao capital próprio (PCT) e a composição do endividamento no curto prazo (CE). A variável PCT possui um índice de 1,82 em média, revelando que as empresas de distribuição e geração de energia estão com o endividamento elevado em relação ao seu patrimônio líquido. A variável CE demonstra que 40\% do total das dívidas da empresa, ou seja, o capital de terceiro é de curto prazo, possuindo em mínimo de $19 \%$ e um máximo de $98 \%$.

Antes de efetuar a análise de Regressão Linear Múltipla, buscou-se analisar inicialmente a intensidade e o sentido das relações entre as variáveis, calculou-se o coeficiente de correlação de Pearson para as variáveis. Observa-se que foi aplicado o teste não paramétrico de Kolmogorov-Smirnov para verificar a normalidade dos dados, o teste evidenciou uma distribuição normal das variáveis a um nível de $5 \%$ ( $p$-value $<0.05$ ).

Além disso, foi aplicado o teste homocedasticidade de Levene que é o mais comum para verificação da homocedasticidade. Conforme observado o teste de Levene não foi significativo, confirmando-se a hipótese de que a variância dos erros é uniforme, ou seja, que a diferença entre as variâncias é igual a zero. Ressalta-se que a correlação não implica necessariamente na relação de causa e feito, mas sim associação entre as variáveis. A Tabela 2 apresenta a correlação entre as variáveis.

Tabela 2 - Matriz de correlação das variáveis

\begin{tabular}{c|c|c|c|c|c}
\hline & SUST & TAMANHO & ROA & PCT & CE \\
\hline SUST & 1 & $0,521^{* *}$ & 0,024 & $-0,040$ & $-0,447^{*}$ \\
\hline TAMANHO & & 1 & $-0,272$ & 0,043 & $-0,706^{* *}$ \\
\hline ROA & & & 1 & 0,146 & 0,328 \\
\hline PCT & & & & 1 & $-0,008$ \\
\hline CE & & & & & 1 \\
\hline
\end{tabular}

* indica signif. a $5 \%$.

** indica signif. a $1 \%$.

Analisando-se as correlações entre as variáveis, apresentadas na Tabela 2, verifica-se, uma correlação positivamente significativa entre o índice de evidenciação da sustentabilidade com uma das variáveis independentes, ou seja, quanto maior o índice de evidenciação da sustentabilidade, maior o tamanho da empresa. Além disso, observa-se que o endividamento a curto prazo foi negativamente relacionado com o índice de evidenciação. Já o retorno sobre o ativo e o endividamento em relação ao patrimônio líquido não foi significativo. Após o cálculo da correlação entre as variáveis utilizadas partiu-se para a análise da regressão linear múltipla, buscando verificar a relação entre o índice de sustentabilidade e os indicadores econômico-financeiros das empresas de energia listadas na BM\&FBovespa. A Tabela 3 apresenta o resumo do modelo da regressão linear múltipla.

Tabela 3 - Resumo do modelo globalmente

\begin{tabular}{c|c|c|c|c|c}
\hline Modelo & $\mathbf{R}$ & $\mathbf{R}$ quadrado & $\begin{array}{c}\text { R quadrado } \\
\text { ajustado }\end{array}$ & Erro padrão da estimativa & Durbin-Watson \\
\hline 1 & 0,576 & 0,332 & 0,229 & 0,167 & 2,193 \\
\hline
\end{tabular}


A tabela acima descreve o modelo globalmente, ela informa se o modelo é eficaz em verificar a relação entre o índice de sustentabilidade e os indicadores econômico-financeiros das empresas de energia listadas na $B M \& F B o v e s p a$. O coeficiente de determinação $\left(\mathrm{R}^{2}\right)$ que serve como uma medida de quanto a variabilidade da saída pode ser debitada aos previsores. O R2 ajustado apresenta um valor pouco representativo, o que significa que as variáveis independentes são responsáveis apenas por $33,20 \%$ da variação do índice de evidenciação ambiental.

Por fim, a estatística de Durbim-Watson informa se a hipótese de independência dos erros é satisfeita, conforme Maroco (2003) o valor deve estar próximo de 2, dessa forma é possível observar que o modelo não apresenta problemas de autocorrelação dos resíduos, pois seu valor está próximo de 2. A Tabela a seguir apresenta a análise de variância, a qual testa se o modelo possui um poder explicativo melhor do que a média para explicar a variável independente.

Tabela 4 - Anova

\begin{tabular}{c|c|c|c|c|c|c}
\hline \multicolumn{2}{c|}{ Modelo } & Soma dos Quadrados & df & Quadrado médio & F & Sig. \\
\hline \multirow{3}{*}{1} & Regressão & 0,361485 & 4 & 0,0903713 & 3,230 & 0,028 \\
\cline { 2 - 7 } & Erro & 0,727469 & 26 & 0,0279796 & & \\
\cline { 2 - 7 } & Total & 1,08895 & 30 & & & \\
\hline
\end{tabular}

Conforme os resultados apresentados pela análise de variância por meio do teste F (Tabela 4) pode-se afirmar que há um nível de significância de $1 \%$, existindo uma forte evidência que as variáveis independentes influenciam significativamente na evidenciação ambiental das empresas pertencentes à amostra. Por fim, apresentam-se os coeficientes de regressão linear múltipla.Tabela 5 - Regressão linear múltipla

Tabela 5 - Regressão linear múltipla

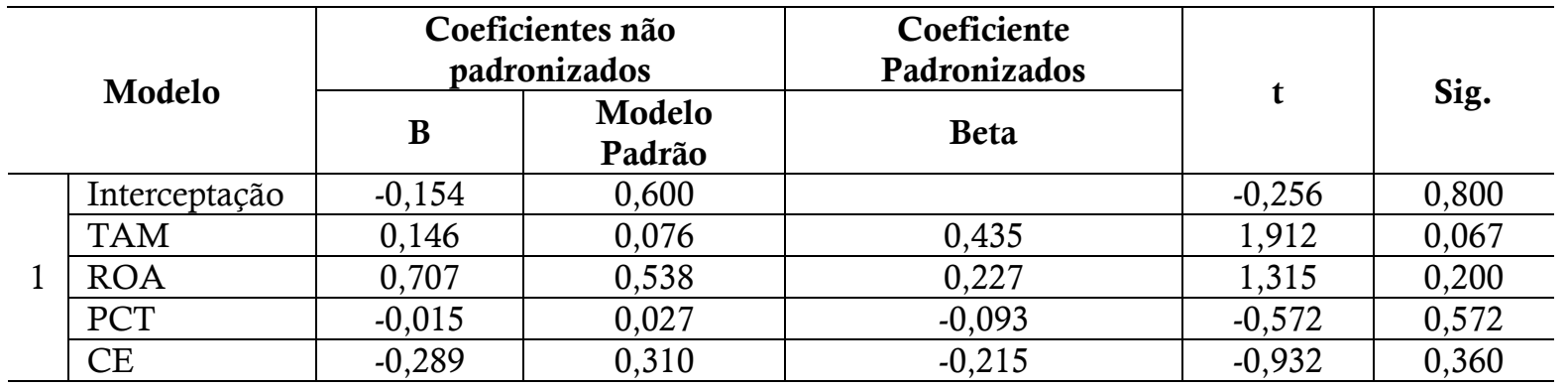

Segundo a Tabela 5 , nenhuma das variáveis independentes econômico-financeiras foram consideradas estatisticamente significante ao nível de $5 \%$ (p-value $<0,05$ ), ou seja, o tamanho, a rentabilidade e o endividamento não influencia significativamente no índice de sustentabilidade das empresas geradoras e distribuidoras de energia elétrica no Brasil que estão listadas na BM\&FBovespa. Além disso, o modelo de explicação é pouco significativo, visto que o R2 foi de apenas 0,332.O resultado relacionado quanto ao retorno dos ativos está de acordo com os encontrados por Hackston e Milne (1996) em pesquisa realizada com empresas da Nova Zelândia. Eles pesquisaram as 50 maiores instituições de diversos setores e também não encontraram relevância estatística da influência do retorno sobre o ativo na divulgação ambiental.

Em relação ao endividamento da empresa, esse achado encontra respaldo no estudo de Braga, Oliveira e Salotti (2009) que analisaram o índice de evidenciação de 108 companhias de capital aberto listadas na BM\&FBovespa referente ao exercício social de 2006. Contudo, o resultado contraria a contribuição de Braga, Oliveira e Salotti (2009) quanto o impacto do tamanho da empresa na evidenciação ambiental, visto que os autores encontraram uma influência positivamente significativa e neste estudo não foi significante. 


\section{CONSIDERAÇÕES FINAIS}

O propósito tomado pela presente pesquisa consiste em verificar a relação entre o índice de sustentabilidade e os indicadores econômico-financeiros das empresas de energia listadas na BM\&FBovespa. A amostra é composta por 31 empresas de geração e distribuição de energia que enviaram seus relatórios de sustentabilidade do ano de 2010 para a Aneel. A escolha deste setor é fundamentada pelo fato de se tratar de um segmento com elevado impacto danoso ao ambiente e com relevância econômica para o país.

O conceito de sustentabilidade está sendo constantemente discutido no âmbito acadêmico e empresarial. Posturas mais transparentes na prestação de informações dos aspectos social e ambiental estão sendo impostas pela sociedade. Com isto, as empresas estão se preocupando mais com seu papel sustentável e os fatores financeiros que isso possa ocasionar para a entidade.

A pesquisa contribuiu para constatar que as empresas da amostra apresentam um alto índice de evidenciação das práticas de sustentabilidade, em torno de $72 \%$ em média, demonstrando a crescente preocupação das empresas em evidenciar essas práticas. Conforme abordado por Tinoco e Robles (2006), a demanda da sociedade pela transparência dos aspectos relacionados à sustentabilidade passou a ganhar espaço e importância entre as informações que são fornecidas pelas organizações.

Com a análise de correlação de Pearson pode-se perceber que existe uma correlação positiva e significativa entre o índice de evidenciação da sustentabilidade com a variável independente tamanho, ou seja, quanto maior o índice de evidenciação da sustentabilidade, maior o tamanho da empresa. Lembrando que a correlação não implica necessariamente na relação de causa e feito, mas sim associação entre as variáveis.

A regressão linear múltipla infere-se que nenhuma das variáveis independentes econômico-financeiras: tamanho, rentabilidade e o endividamento influenciam significativamente no índice de sustentabilidade das empresas geradoras e distribuidoras de energia elétrica no Brasil que estão listadas na BM\&FBovespa. Além disso, o modelo de explicação é pouco representativo, pois as variáveis independentes são responsáveis apenas por $33,20 \%$ da variação do índice de evidenciação ambiental.

A presente pesquisa está de acordo com o estudo realizado por Hackston e Milne (1996) com empresas de Nova Zelândia a respeito do retorno sobre o ativo (ROA), pois não houve influência na evidenciação ambiental. Mas, encontra-se em desacordo se tratando da variável tamanho, pois Hackston e Milne (1996) justificaram o nível de evidenciação das companhias por meio das variáveis setor e tamanho. E isto não ocorreu neste estudo, pois a variável tamanho não apresentou significância na regressão linear múltipla (sig. 0,067).

Braga, Oliveira e Salotti (2009) avaliaram a influência das variáveis: tamanho, desempenho, endividamento, riqueza criada, natureza da atividade, controle acionário e governança corporativas sobre o nível de divulgação ambiental de empresas brasileiras. Comparando os resultados deste estudo com a pesquisa de Braga, Oliveira e Salotti (2009), percebe-se que nas duas as variáveis de endividamento não tiveram significância sobre o índice de evidenciação da sustentabilidade. Mas, quanto ao impacto do tamanho da empresa na evidenciação ambiental, houve resultados contrários, visto que os autores encontraram uma influência positivamente significativa e neste estudo não foi significante.

O resultado demonstra que se a empresa apresenta um bom índice de evidenciação das práticas de sustentabilidade, ela pode ou não ser de grande porte; pode ser mais ou menos rentável; e mais ou menos endividada do que aquela empresa que apresenta um baixo índice sustentável, ou seja, os indicadores econômico-financeiros do tamanho, rentabilidade e endividamento das empresas geradoras e distribuidoras de energia elétrica brasileira não influenciam o nível de evidenciação das práticas de sustentabilidade destas companhias.

Como sugestão para futuros estudos, salienta-se que outras variáveis poderiam ser utilizadas para verificar a influência na evidenciação das práticas de sustentabilidade nas três dimensões que o desenvolvimento sustentável deve atender: econômico, social e ambiental (ELKINGTON, 2012). Poderia ser utilizada outro grupo na amostra da pesquisa, que não seja as empresas geradoras e distribuidoras de energia listadas na BM\&FBovespa, e também outro período.

\section{REFERÊNCIAS}


AZEVEDO, A. L. V. Indicadores de sustentabilidade empresarial no Brasil: uma avaliação do Relatório do CEBDS. Revista Iberoamericana de Economia Ecológica, v. 5, p. 75-93, 2006.

BERTAGNOLLI, D. D. O.; OTT, E.; DAMACENA, C. Estudo sobre a influência dos investimentos sociais e ambientais no desempenho econômico das empresas. In: CONGRESSO USP, 6., 2006, São Paulo. Anais... São Paulo, FEA/USP, 2006.

BEUREN, I. M. (Org.). Como elaborar trabalhos monográficos em contabilidade: teoria e prática. 2. ed. São Paulo: Atlas, 2004.

BEUREN, I. M. et al. Adequação da evidenciação social das empresas de capital aberto no relatório da administração e notas explicativas às recomendações da NBC T 15. Revista de Contabilidade e Organizações, v. 4, n. 8, p. 47-68, 2009.

BRAGA, J. P.; OLIVEIRA, J. R. S.; SALOTTI, B. M. Determinantes do Nível de Divulgação Ambiental nas Demonstrações Contábeis de Empresas Brasileiras. Revista Contabilidade UFBA, Salvador-Ba, v. 3, n. 3 p. 81-95, 2009.

CAPRA, F. As conexões ocultas: ciência para uma vida sustentável. São Paulo: Cultrix, 2005.

CILIBERTI, F.; PONTRANDOLFO, P.; SCOZZI, B. Investigating corporate social responsability in suply chains: a SME perspective. Journal of Cleaner Production. v. 16, n. 15, p. 1579-1588, 2008.

CRESWELL, J. Qualitative, quantitative and mixed methods approaches. Los Angeles: SAGE Publications Ltd., 2009.

CUNHA, J. V. A.; RIBEIRO, M. S. Divulgação voluntária de informações de natureza social: um estudo nas empresas brasileiras. Revista de Administração - Eletrônica, v.1, n.1, 2008.

D'ARCIMOLES, C.; TREBUCQ, S. The Corporate Performance - Financial Performance Link: Evidence from France. Univ. of Bordeaux Dept. of Int'l Acc'tg. Working Paper No. 02-01. Mar. 2002. Disponível em: $<$ http://papers.ssrn.com/abstract=306599>. Acesso em: 30 Ago. 2013.

DALMÁCIO, F. Z.; PAULO, F. F. M. D. A evidenciação contábil: publicação de aspectos sócio-ambientais e econômico-financeiros nas demonstrações contábeis. In: CONGRESSO USP, 4., 2004, São Paulo. Anais... São Paulo, FEA/USP, 2004.

DI DOMENICO, D. Características das empresas de capital aberto e indicadores da contabilidade de gestão ambiental. Dissertação (Mestrado em Ciências Contábeis) - Universidade Regional de Blumenau - FURB. Blumenau, 2012.

DREHER, M. T.; CASAGRANDE, R. M.; GOMES, G. Inovação e sustentabilidade: desafios da consultoria ambiental. In: XV SEMINÁRIOS EM ADMINISTRAÇÃO, 15., 2012, São Paulo. Anais... São Paulo, SEMEAD, 2012.

ELKINGTON, J. Sustentabilidade, canibais com garfo e faca. São Paulo: M. Books do Brasil, 2012.

HACKSTON, D.; MILNE, M. J. Some determinants of social and environmental disclosure in New Zealand companies. Accounting, Auditing and Accountability Journal, v.9, n.1, p.77-108, 1996.

HOLDREN, P. J.; EHRLICH, R. P. Global ecology: reading toward a rational strategy for man. New York: Harcout Brace Jovanovich, 1971.

IBGC - Instituto Brasileiro de Governança Corporativa. Origem da boa governança. 2007. Disponível em: <http://www.ibgc.org.br/Secao.aspx?CodSecao=18>. Acesso em: 03 maio 2013. 
KOLK, A. Environmental reporting by multinationals from the Triad: convergence or divergence? Management International Review, v. 45, n. 1, special issue, p. 145-166, 2005.

KPMG. International survey of corporate responsibility reporting. 2011. Disponível em: <http://www.kpmg. com/PT/pt/IssuesAndInsights/Documents/corporate-responsibility2011.pdf>. Acessado em: 30 ago. 2013.

LANZANA, A. P. Relação entre evidenciação e governança corporativa das empresas brasileiras. Dissertação (Mestrado em Administração). FEA/USP, São Paulo, 2004.

MARCONI, M. A.; LAKATOS, E. M. Técnicas de pesquisa: planejamento e execução de pesquisas, amostragens e técnicas de pesquisas, elaboração, análise e interpretação de dados. 5. ed. São Paulo: Atlas, 2002.

MAROCO, J. Análise estatística com utilização do SPSS. 2. Ed. Ver. e corr. Lisboa: Sílabo, 2003.

MILES, M. P.; COVIN, J. G. Environmental marketing: a source of reputational, competitive, and financial advantage. Journal of Business Ethics, v. 23, n. 3, p. 299-311, 2000.

MUSSOI, A.; VAN BELLEN, H. M. Evidenciação ambiental: uma comparação do nível de evidenciação entre os relatórios de empresas brasileiras. Revista de Contabilidade e Organizações, v. 4, n. 9, p. 55-78, 2010.

NOSSA,V. Disclosure Ambiental: Uma Análise do Conteúdo dos Relatórios Ambientais de Empresas do Setor de Papel e Celulose em Nível Internacional. Tese (Doutorado) Departamento de Contabilidade e Atuaria da Faculdade de Economia, Administração e Contabilidade da Universidade de São Paulo. São Paulo, 2002.

NUNES, J. G. et al. Análise das variáveis que influenciam a adesão das empresas ao índice BM\&F Bovespa de sustentabilidade empresarial. BASE - Revista de Administração e Contabilidade da Unisinos, v.7, n.4, p. 328-340. 2010.

ORLITZKY, M; SCHMIDT, F. L; RYNES, S. R. Corporate social and financial performance: a meta-analysis. Organization Studies, v. 24, n. 3, p. 403-441, 2003.

PARENTE, J.; GELMAN, J. J. Varejo e responsabilidade social, visão estratégica e práticas no Brasil. Porto Alegre: Bookman, 2006.

POLONSKI, M. J.; SUCHARD, H. T.; SCOTT, D. A stakeholder approach to interacting with the external environment. Australia and New Zealand Marketing Educators Conference Proceedings, p. 495-508, 1997.

PONTE, V. M. R.; OLIVEIRA, M. C. A prática da evidenciação de informações avançadas e não obrigatórias nas demonstrações contábeis das empresas brasileiras. Revista Contabilidade \& Finanças, v. 15, n. 36, p. 7-20, 2004.

RICHARDSON, R. J. Pesquisa social: métodos e técnicas. 2. ed. São Paulo: Atlas, 1999.

ROVER, S.; BORBA, J. A.; MURCIA, F. D.; VICENTE, E. F. R. Divulgação de informações ambientais nas demonstrações contábeis: um estudo exploratório sobre a evidenciação das empresas brasileiras pertencentes a setores de alto impacto ambiental. RCO - Revista de Contabilidade e Organizações, FEARP/USP, v. 2, n. 3, p. 53 - 72 mai./ago, 2008.

RUSSO, M. V; FOUTS, P. A. A resource-based perspective on corporate environmental performance and profitability. Academy of Management Journal, v. 40, n. 3, p.534-559, 1997.

SACHS, I. Caminhos para o desenvolvimento sustentável. Rio de Janeiro: Garamond, 2009.

SACHS, I.; LOPES, C.; DOWBOR, L. Crises e oportunidades em tempos de mudança. Economia Global e 
Gestão, v. 15, n. 1, p. 133-154, 2010.

SIMON, H. A behavioral model of rational choice. The Quarterly Journal of Economics, v. 69, n. 1, p. 99-118, 1971.

TINOCO, J. E. P.; KRAEMER, M. E. P. Contabilidade e Gestão Ambiental. 3. ed. São Paulo: Atlas, 2011.

TINOCO, J. E. P.; ROBLES, L. T. A contabilidade da gestão ambiental e sua dimensão para a transparência empresarial: estudo de caso de quatro empresas brasileiras com atuação global. Revista de Administração Pública, v. 40, n. 6, p. 1077-1096, 2006.

VON ARX, U.; ZIEGLER, A. The effect of corporate social responsibility on stock performance: new evidence for the USA and Europe. In: Swiss Society of Economics and Statistics-Globalization: Patterns and Challenges Conference. 2008.

WCED (World Commission on Environment and Development). Our Common Future; Oxford University Press: Oxford, UK, 1987. 